Article

\title{
Estimating Relative Efficiency of Electricity Consumption in 42 Countries during the Period of 2008-2017
}

\author{
Chia-Nan Wang ${ }^{1,2}$, Quoc-Chien Luu ${ }^{1, *(\mathbb{D})}$ and Thi-Kim-Lien Nguyen ${ }^{1}$ \\ 1 Department of Industrial Engineering and Management, National Kaohsiung University of Science and \\ Technology, Kaohsiung 80778, Taiwan; cn.wang@nkust.edu.tw (C.-N.W.); \\ lien.nguyen0209@gmail.com (T.-K.-L.N.) \\ 2 Department of Industrial Engineering and Management, Fortune Institute of Technology, \\ Kaohsiung 83160, Taiwan \\ * Correspondence: jkie2211@gmail.com; Tel.: +886-097-965-2251
}

Received: 26 September 2018; Accepted: 31 October 2018; Published: 5 November 2018

\begin{abstract}
Augmentation of electrical equipment is pushing for an increase in energy supply sources all over the world, as electricity consumption (EC) typically rises with growing populations. The value of EC reveals economic development and degree of emissions. Therefore, this research uses the undesirable outputs model in data envelopment analysis (DEA) for estimating relative efficiency of electricity consumption in 42 countries from 2008 to 2017. According to the principle of an undesirable outputs model and studied objectives, variables are selected that included population and EC as inputs, gross domestic product (GDP) as desirable output, and carbon dioxide $\left(\mathrm{CO}_{2}\right)$, methane $\left(\mathrm{CH}_{4}\right)$, and nitrous oxide $\left(\mathrm{N}_{2} \mathrm{O}\right)$ as undesirable outputs. The empirical results indicate that 420 terms of 42 countries during the period of 2008-2017 have 102 efficient and 310 inefficient terms. Moreover, the interplay level between input and output factors every year is presented via scores. The study suggests the effect of EC to human life and propounds the emission status to look for directions to overcome inefficient terms.
\end{abstract}

Keywords: electricity consumption (EC); undesirable outputs model; data envelopment analysis (DEA); efficient; inefficient

\section{Introduction}

In modern life, electrical energy is essential to meet the demands of extending technology and electronic equipment [1], as electricity provides energy for lighting, heating, cooling, factories, machines, transportation systems, i.e., [2]. The increasing population leads to increasing electricity consumption (EC); thus, population growth and EC have a significant positive relationship [3]. When electricity is utilized, it contributes to enhancing the economic development index. Lu indicated that a 1\% increase in EC from 17 Taiwanese industries boosted the real GDP by 1.72\% [4]; Enu and Patrick explained the effect of EC on economic growth in Ghana [5]; Altisnay and Karagol showed the casual relationship between EC and real GDP in Turkey [6]. On the other hand, EC causes pollutant emissions to the environment, including $\mathrm{CO}_{2}, \mathrm{CH}_{4}$, and $\mathrm{N}_{2} \mathrm{O}$. For instance, a study by the Federal University of Agriculture Abeokuta assessing carbon footprints over the 2011-2012 period showed that 5935 tons of $\mathrm{CO}_{2}$ represented $63 \%$ transportation, 35\% campus energy consumption, and $2 \%$ farm machineries per student [7]. In Hong Kong, between 2002 and 2015, the annual EC went from 27 to 34.1 million tons; further, $\mathrm{CO}_{2}$-eq/kWh was increased from 702 to $792 \mathrm{~g}$ [8]. Therefore, EC has a positive and significant relationship with both emissions [9,10] and economic growth [11].

Electricity is generated from two sources, i.e., nonrenewable and renewable energy. Renewable energy comprises hydropower, biomass, wind, solar, and geothermal. Nonrenewable energy consists of oil, 
natural gas, coal, and nuclear. Both sources are applied to generating electricity to provide energy for inhabitants and their applications [12]. The population increase augments the EC as well. When a consumer uses electrical energy, economic growth is extended, and $\mathrm{CO}_{2}, \mathrm{CH}_{4}$, and $\mathrm{N}_{2} \mathrm{O}$ rise as well. Increased emissions lead to polluted environments and climate change. Thus, the purpose of study is to determine the relationship among inputs (population, and EC), desirable output (GDP), and undesirable outputs (emissions), the relation is evaluated via the scores computed by an undesirable outputs model in DEA.

In DEA, the super-SBM, EBM, and Malmquist models can formulate the maximum score and separate values for each decision-making unit (DMU) in every term; however, they cannot deal with desirable and undesirable outputs, whereas an undesirable outputs model only approaches to the highest value of 1 , but it can solve with good (desirable) and bad (undesirable) outputs independently [13]. This model reaches bad factors in the operation process; the inefficient DMUs will be suggested, i.e., raising good outputs while simultaneously reducing bad outputs to improve their scores $[14,15]$. With these characteristics, the study applies an undesirable outputs model into computing the efficiency of EC with its relative elements in 42 countries over the world from 2008 to 2017. The analysis result works out the influence of EC on the economic development, and emissions in which the increased levels of undesirable emissions are the root causes of climate change. A feasible solution is recommended to refine the performance of inefficient terms. Moreover, the study draws a picture of the productivity efficiency between EC and its relative factors in 42 countries over the years.

The study is arranged as follows: Section 1 shows the general points of electricity's application, producing an electricity process, and its effects; Section 2 overviews EC and its background research, the theoretical concept of undesirable outputs model in undesirable model and its application; Section 3 builds upon the proposal research and methodology, and quotes source materials; Section 4 displays the empirical analysis results; Section 5 comments on the general results, gives limitations, and discusses future research.

\section{Literature Review}

The life of people without electricity was inconvenient, they worked by manual labour, and lived without light. Since electrical energy was invented in the18th century, the life of inhabitants has been changed with access to light, electronic equipment, and high-tech. The effectiveness of production operations is enhanced and upgraded sharply by the use of electrical machines. The process whereby people use electrical energy for lighting, heating, transportation, and so on is called "electricity consumption". The population is the major source that supports electricity development when utilizing electronic equipment. The electricity is consumed at a high or low level, the EC reflects an economic growth level. Chen denoted that the economic growth and population have a vital role on the electrical energy consumption when depending on the non-parametric model [16]. To explore the electricity demand in the future, Gajowniczek [17] displayed an approach to predict electricity load at the individual household level using CART, SVM and a MLP neutral network model; Gajowniczek continued studying electricity demand [18]; Singh [19] proposed Bayesian network prediction for energy usage forecasting.

On the other hand, the electricity causes greenhouse gas [20] that leads to climate change because of the emission of $\mathrm{CO}_{2}, \mathrm{CH}_{4}, \mathrm{~N}_{2} \mathrm{O}$ [21] from electricity production processes [22]. Emissions from hydropower are estimated by using statistical global emission models through the reservoir water surface [23,24], that from natural gas and coal power plants is calculated by a simple model [25], and that from combustion power plants is counted by the values and data of emission factors exhausted from the circulating fluidized bed boiler [26], or that from wind power plants is formulated by a simple analysis method for the undesirable elements of electricity production processes [27]. In China emissions from EC are determined by a data analysis and measurement method [28], while in the United States a transparent method is used [29]. Hence, the previous researchers applied various methods to an examination of the emission of undesirable factors from EC. 
Whereas DEA normally concerns calculating performance with the inputs and good outputs in various models such as dynamic-SBM, super-SBM, EBM, i.e., however, they cannot solve for undesirable outputs in social activities, air pollution, and the industrial manufacturing sector. For this reason, Tone proposed an undesirable outputs model in DEA to evaluate bad outputs [30], displaying a new scheme. A DMU acquires efficiency as the score approaches 1 , and it is inefficient when the score is less than 1 . Furthermore, the model can compute the performance by combining both undesirable and desirable outputs [31]. The efficiency valuations indicate not only the interplay between desirable and undesirable outputs, but also the ranking of each DMU in every year [32]. Many researchers have applied the undesirable model into their studies. For example, an analysis by the Organization for Economic Co-operation and Development (OECD) of countries with population and energy consumption as input factors, GDP as desirable output, and $\mathrm{CO}_{2}$ as undesirable output reveals the environmental efficiency [33]; the overall efficiency of the United States's electricity production is evaluated by escalating the desirable output and undesirable outputs [34]; counting the efficiency shows the relationship between labor force, energy consumption, government expenditure as input, GDP as desirable output, and $\mathrm{CO}_{2}$ emissions as undesirable output [35]. Moreover, the undesirable model is used for examining performance in other aspects such as estimating the impact of production pollutants in the textile industry of China with inputs like labor, and energy, yam and fabric as desirable outputa, and wastewater as undesirable [36]. In addition, the researchers also utilized an undesirable model to analyze and evaluate efficiency in the energy sector. Measuring between inputs including gross fixed capital formation, labor and energy consumption and outputs including $\mathrm{CO}_{2}$ (undesirable output), and GDP (desirable output) indicated the energy performance in Brazil, Russia, India, China, and South Africa [37].

With the principle of the undesirable outputs model and its previous applications, the paper proposed undesirable outputs model of DEA to analyze the interplay between inputs such as population and $\mathrm{EC}$ and outputs such as GDP, $\mathrm{CO}_{2}, \mathrm{CH}_{4}, \mathrm{~N}_{2} \mathrm{O}$ in the electricity production aspect of 42 countries during the $2008-2017$ term.

\section{Methodology}

\subsection{Proposal Research}

Our study of the electricity performance process in 42 countries is organized into four steps as shown in Figure 1:

- Step 1: Present the purpose of the selected topic, input, and output variables. The theme and data must be reselected if they are inappropriate. The suitable materials of electricity, as listed on Enerdata [38], Worldbank [39], and Epa [40], are collected. Then, the EC from all over the world is introduced and factors relating the production process with EC are described.

- Step 2: Show the benefits of electricity. The study overviews EC and its influences on the environment; and the undesirable model theory is used to demonstrate in feasibility of the method. Especially, previous studies that relate to EC and the undesirable model to indicate a probability theme are discussed.

- Step 3: The first stage of the analysis process must check the Pearson coefficient to ensure the data is isotonic; any value does not range from -1 to +1 it must be removed and reselected. Next, the suitable values are applied into an undesirable outputs model to compute scores. The scores are used for determining the efficiency/inefficiency of 42 countries over the years. The scores propound their ranking over each term as well. The empirical results present a stable or upward and downward interplay of countries during the period of 2008-2017 in particular. Moreover, the analysis results suggest the current status of the effect level in each year when utilizing electrical energy.

- Step 4: Manifest main points of the empirical results of efficient/inefficient countries, and ranking, in addition to recommendations on the analysis of a variable pathway of each country in every year. The suggestion points out improvements for inefficient countries. 


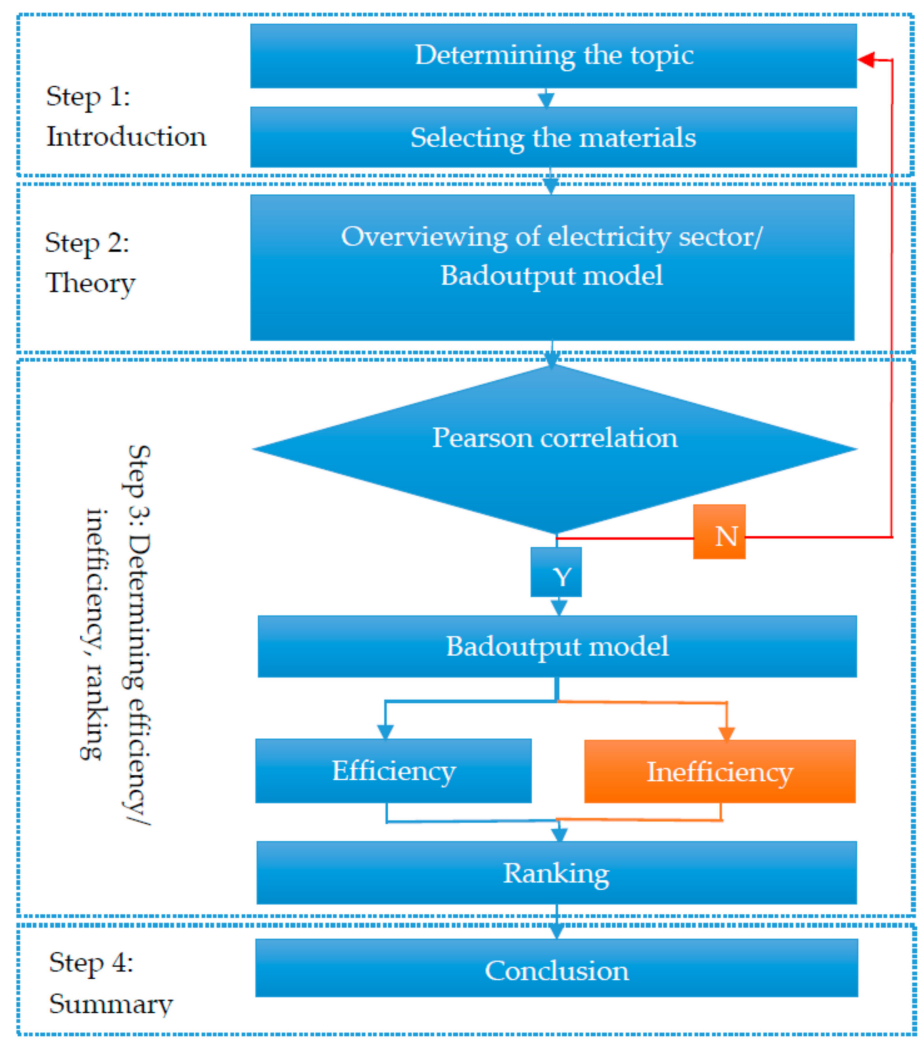

Figure 1. Proposal research.

\subsection{Data Source}

Electricity is a source fuel that provides lighting, heating, cooling, and runs electronics, machinery, and transportation systems. Hence, in modern life with the increasing use of diverse high-tech and electrical equipment, electricity is an essential element. While on the subject, the research discovers electricity consumption levels and their relative factors. Based on the input and output data posted on websites, including electricity consumption on Enerdata [38], population and GDP on Worldbank [39], emissions, including $\mathrm{CO}_{2}, \mathrm{CH}_{4}$, and $\mathrm{N}_{2} \mathrm{O}$, are computed when their equations are based on the Epa version 3.2 of June 2014 [40]. The 42 countries selected from Enerdata [38] to estimate the performance as listed in Table 1.

Table 1. Name of countries.

\begin{tabular}{cccccc}
\hline No & Country & No & Country & No & Country \\
\hline 1 & Belgium & 15 & Kazakhstan & 29 & Japan \\
2 & Czech Republic & 16 & Russia & 30 & Malaysia \\
3 & France & 17 & Ukraine & 31 & South Korea \\
4 & Germany & 18 & Uzbekistan & 32 & Thailand \\
5 & Italy & 19 & Canada & 33 & Australia \\
6 & Netherlands & 20 & United States & 34 & New Zealand \\
7 & Poland & 21 & Argentina & 35 & Algeria \\
8 & Portugal & 22 & Brazil & 36 & Egypt \\
9 & Romania & 23 & Chile & 37 & Nigeria \\
10 & Spain & 24 & Colombia & 38 & South Africa \\
11 & Sweden & 25 & Mexico & 39 & Iran \\
12 & United Kingdom & 26 & China & 40 & Kuwait \\
13 & Norway & 27 & India & 41 & Saudi Arabia \\
14 & Turkey & 28 & Indonesia & 42 & United Arab Emirates \\
\hline \multicolumn{5}{c}{ Source: Enerdata [38]. }
\end{tabular}


Characteristics of each variable are described as follows:

- $\quad$ Population (Input): When the population of a nation increases, the electricity usage increases because the amount of electronic equipment will be augmented as well.

- $\quad$ Electricity consumption (Input): The electricity is consumed by providing electrical energy for light, heating, cooling, machines, and so on.

- GDP (desirable output): The economic performance of every country is measured by market value. In the electricity sector, the volumes of EC are used by consumers for any application, i.e., they contribute to extending GDP indicators.

- $\mathrm{CO}_{2}, \mathrm{CH}_{4}, \mathrm{~N}_{2} \mathrm{O}$ (undesirable outputs): Coal, oil, natural gas, and biomass are burned in combustion power plants. Nuclear power plants create heat, in addition to the heat of the Sun in solar power, turbines in hydropower plants via the energy power of water from natural waterfalls, tides, and flowing rivers create electricity, or turbines in wind power plants by the wind's energy. These processes all generate electricity, then the generation electricity is transmitted to customers via wires. When the electrical energy is consumed, the EC process produces emissions, including $\mathrm{CO}_{2}, \mathrm{CH}_{4}$, and $\mathrm{N}_{2} \mathrm{O}$.

\subsection{Undesirable Outputs Model}

The undesirable outputs model is utilized to calculate the performance of DMUs when its outputs obtain undesirable outputs. In this study, the undesirable outputs model is applied to deal with good (desirable) and (bad) (undesirable) outputs. We utilize an undesirable outputs model to compute the efficiency of the electrical energy consumption in 42 countries. The DMUs are the 42 countries, these countries are set up n DMU $\left(a_{0}, b_{0}\right)(n=1,2, \ldots, s)$. Let the input factor be A, desirable factor $\left(B^{d}\right)$, and undesirable factor $\left(B^{u}\right)$. Then, the production possibility is given by:

$$
P=\left\{\left(a, b^{d}, b^{u}\right), a \geq X \lambda ; b^{d} \leq B^{d} \lambda ; b^{u} \geq B^{u} \lambda ; L \leq e \lambda \leq U, \lambda \geq 0\right\}
$$

The intensity vector is $\lambda$, it means that the above definition corresponds to the constant return to scale technology [41], and the lower and upper bounds of the intensity vector are $L$ and $U$, respectively $\left(e=(1, \ldots 1) \in R^{+}, L \leq 1, U \geq 1\right)$. There is at least one strict inequality when formulating the efficiency of one DMU $\left(a_{0}, b_{0}^{d}, b_{0}^{u}\right)$ without vector $\left(a_{0}, b_{0}^{d}, b_{0}^{u}\right) \in P$ and $a_{0} \geq a, b_{0}^{d} \leq b^{d}, b_{0}^{u} \geq b^{u}$. According to the SBM of Tone [42], the objective function of the undesirable model is formulated as follows:

$$
\rho^{*}=\min \frac{1-\frac{1}{k} \sum_{i=1}^{k} \frac{s_{i}^{-}}{a_{i 0}}}{1+\frac{1}{s}\left(\sum_{r=1}^{s_{1}} \frac{s_{r}^{d}}{b_{r o}^{d}}+\sum_{r=2}^{s_{1}} \frac{s_{r}^{u}}{b_{r o}^{u}}\right)}
$$

Subject to:

$$
\begin{gathered}
a_{0}=A \lambda+s^{-} \\
b_{0}^{d}=B \lambda-s^{d} \\
b_{0}^{u}=B \lambda+s^{u} \\
s^{-}, s^{d}, s^{u}, \lambda \geq 0 .
\end{gathered}
$$

The excess in inputs, bad outputs and shortages in good outputs are $s^{-}, s^{u}, s^{d}$, respectively. The number of factors in $s^{u}$ and $s^{d}$ are $s_{1}$ and $s_{2}$, respectively, and $s=s_{1}+s_{2}$. Using an optimal solution as $\rho^{*}, s^{-^{*}}, s^{d^{*}}$ and $s^{u^{*}}$ for determining the efficiency of country by undesirable outputs when $\rho^{*}=1$, $s^{-^{*}}=0, s^{d^{*}}=0$, and $s^{u^{*}}=0$. When the DMU is inefficient, $\rho^{*}$ can be improved in order to become 
efficient by moving the excesses in inputs and bad outputs, simultaneously increasing the shortfalls in good outputs [42] as follows:

$$
\begin{aligned}
a_{0}-s^{-*} & \Rightarrow a_{0} \\
b_{0}^{d}+s^{d *} & \Rightarrow b_{0}^{d} \\
b_{0}^{u}-s^{u *} & \Rightarrow b_{0}^{u}
\end{aligned}
$$

The above program was transformed into an equivalent linear program by Charnes and Cooper [43]. Let the dual variable vectors be $x, y^{d}, y^{u}$. Based on the dual side of the linear program, the dual program in the variable $x, y^{d}, y^{u}$ for constant return to scale [30] is defined as below:

$$
\max y^{d} b_{0}^{d}-x a_{0}-y^{u} b_{0}^{u}
$$

Subject to:

$$
\begin{aligned}
& y^{d} B^{d}-x A-y^{u} B^{u} \leq 0 \\
& x \geq \frac{1}{k}\left[\frac{1}{a_{0}}\right] \\
& y^{d} \geq \frac{1+y^{d} b_{0}^{d}-x a_{0}-y^{u} b_{0}^{u}}{s}\left[\frac{1}{b_{0}^{d}}\right] \\
& y^{u} \geq \frac{1+y^{d} b_{0}^{d}-x a_{0}-y^{u} b_{0}^{u}}{s}\left[\frac{1}{b_{0}^{u}}\right]
\end{aligned}
$$

The virtual prices of inputs, desirable and undesirable outputs are replaced by the dual variables $x, y^{d}, y^{u}$ respectively. The profit $y^{d} b^{d}-x a-y^{u} b^{u}$ [30] does not exceed zero for every DMU, and the profit $y^{d} b_{0}^{d}-x a_{0}-y^{u} b_{0}^{u}$ for the DMU concerned when the dual program aims at obtaining the optimal virtual costs and prices for each DMU.

In addition, we set $w_{1} \in R^{+}, w_{2} \in R^{+}$as the weights of desirable and undesirable outputs, respectively. The weights of bad and good outputs are converted to relative weights with their mathematical expression [30] as follows:

$$
\rho^{*}=\min \frac{1-\frac{1}{k} \sum_{i=1}^{k} \frac{s_{i o}^{-}}{a_{i o}}}{1+\frac{1}{k}\left(W_{1} \sum_{r=1}^{s_{1}} \frac{s_{r}^{d}}{b_{r o}^{d}}+W_{2} \sum_{r=1}^{s_{2}} \frac{s_{r}^{u}}{b_{r o}^{u}}\right)} .
$$

Subject to:

$$
\begin{aligned}
& W_{1}=\frac{s w_{1}}{w_{1}+w_{2}} . \\
& W_{2}=\frac{s w_{2}}{w_{2}+w_{1}} . \\
& \left(w_{1} \geq 0, w_{2} \geq 0\right) .
\end{aligned}
$$

Consequently, if $\rho^{*}<1$, the country is inefficient so the excesses in inputs and undesirable outputs must be removed, and the shortfalls in desirable outputs must be increased. A country reaches efficiency when $\rho^{*}=1$.

\section{Results}

Based on the data in Section 3.2, the study utilizes an undesirable outputs model in DEA to analyze inputs and desirable and undesirable variables that relate to EC.

\subsection{Data Analysis}

Tables A1 and A2 indicate the summarized statistics of input/output factors of 42 countries. In 2017, the values of population, $\mathrm{EC}, \mathrm{CO}_{2}, \mathrm{CH}_{4}, \mathrm{~N}_{2} \mathrm{O}$, and GDP attained a maximum of 1,386,395,000, $5683.42,3779.929,0.2102,0.0394$, and 19,390,604, respectively. The minimum values of population, EC, 
$\mathrm{CO}_{2}$, and GDP are 2,652,340, 18.051, 12.0054, and 29,549.44, in 2008, 2009, 2009, and 2008, respectively. $\mathrm{CH}_{4}$ and $\mathrm{N}_{2} \mathrm{O}$ have minimum values of $0.0007,0.0001$, respectively, within 2008-2010.

DEA is sensitive to outliers so that the data are tested for measurement errors. The tested results indicate the presence and significance of variables. The outlier detection in the data is checked by using the SPSS software. Table A3 denotes that all cases are valid. Electricity consumption, GDP, $\mathrm{CO}_{2}, \mathrm{CH}_{4}$, and $\mathrm{N}_{2} \mathrm{O}$ have a small difference excluding population as shown in Figure A1; however, the populations are important for the electricity consumption, so this factor is still kept to take part in the analysis process.

Moreover, before the data are applied to analysis by models in DEA, they must be checked via Pearson correlation between input variables and output variables to ensure "isotonicity". The values of the correlation coefficient range from -1 to +1 . We have a perfect linear relationship between two variables if the correlation coefficient is equal to 1 . On the contrary, the variable must be removed and reselected when the correlation coefficient is not positive and significant. As shown in Tables A4 and A5, the Pearson correlations of 42 countries in the research range from 0.303741 to 1 ; thus, the input and output factors have a standard qualification.

\subsection{Efficienct and Inefficient Terms}

As per the math in Section 3.3, the countries acquire efficiency when their scores are equal to 1; they are inefficient if their scores are under 1 . Table 2 denotes the scores of every country in each term; the scores account for efficient and inefficient terms as well. Belgium, Czech Republic, France, Italy, Poland, Romania, Spain, Sweden, Turkey, Kazakhstan, Russia, Ukraine, Uzbekistan, Canada, Argentina, Brazil, Chile, China, India, Indonesia, Malaysia, South Korea, Thailand, Egypt, South Africa, Iran, Saudi Arabia, and United Arab Emirates are inefficient countries in whole terms because their scores are always lower than 1. Germany achieved efficiency during the period of 2008-2011 and 2013-2014 with its score at 1; however, it proved inefficient in 2012, 2015, 2016, and 2017, as its scores are $0.9062,0.776,0.9115$, and 0.9861 , respectively. The Netherlands attained performance except it remained inefficient in 2015 with a score of 0.9601 . Portugal remained efficient from 2008 to 2016, but the growth of modern society led to increased consumption of electricity, which further led to increased $\mathrm{CO}_{2}, \mathrm{CH}_{4}$, and $\mathrm{N}_{2} \mathrm{O}$ emissions in 2017; as a consequence, it remained inefficient in 2017 with a score of 0.9999 . Colombia approached efficiency from 2011 to 2013 and excluding inefficient terms from 2014 to 2017 , had scores of $0.7522,0.7069,0.9692,0.7257,0.5765,0.517$, and 0.5291 , respectively. Mexico remained inefficient for nine years, as its scores were from 0.2847 to 0.3641 , although its score reached 1 in 2015. Japan was efficient during 2009-2011 and inefficient in 2008 and 2012-2017, when its scores were $0.8572,0.8379,0.7002,0.6128,0.7925$, and 0.6942 , respectively. Australia achieved efficient performance status during 2010-2015 and in 2017; its scores in 2008, 2009, and 2016 were 0.6228, 0.5712, and 0.8924, respectively. New Zealand remained efficient from 2009 to 2017, excluding 2008, as its score is 0.7689. Algeria achieved efficiency from 2008 to 2010, but remained inefficient during 2011-2017, as its scores are under 1. Besides, five countries, including the United Kingdom, Norway, United States, Nigeria, and Kuwait, were assigned as efficient in the whole term, as their results compute to be 1 . Further, these results reveal the ratio among inputs and desirable and undesirable outputs at the balance level. 
Table 2. Scores of 42 countries over the period of 2008-2017.

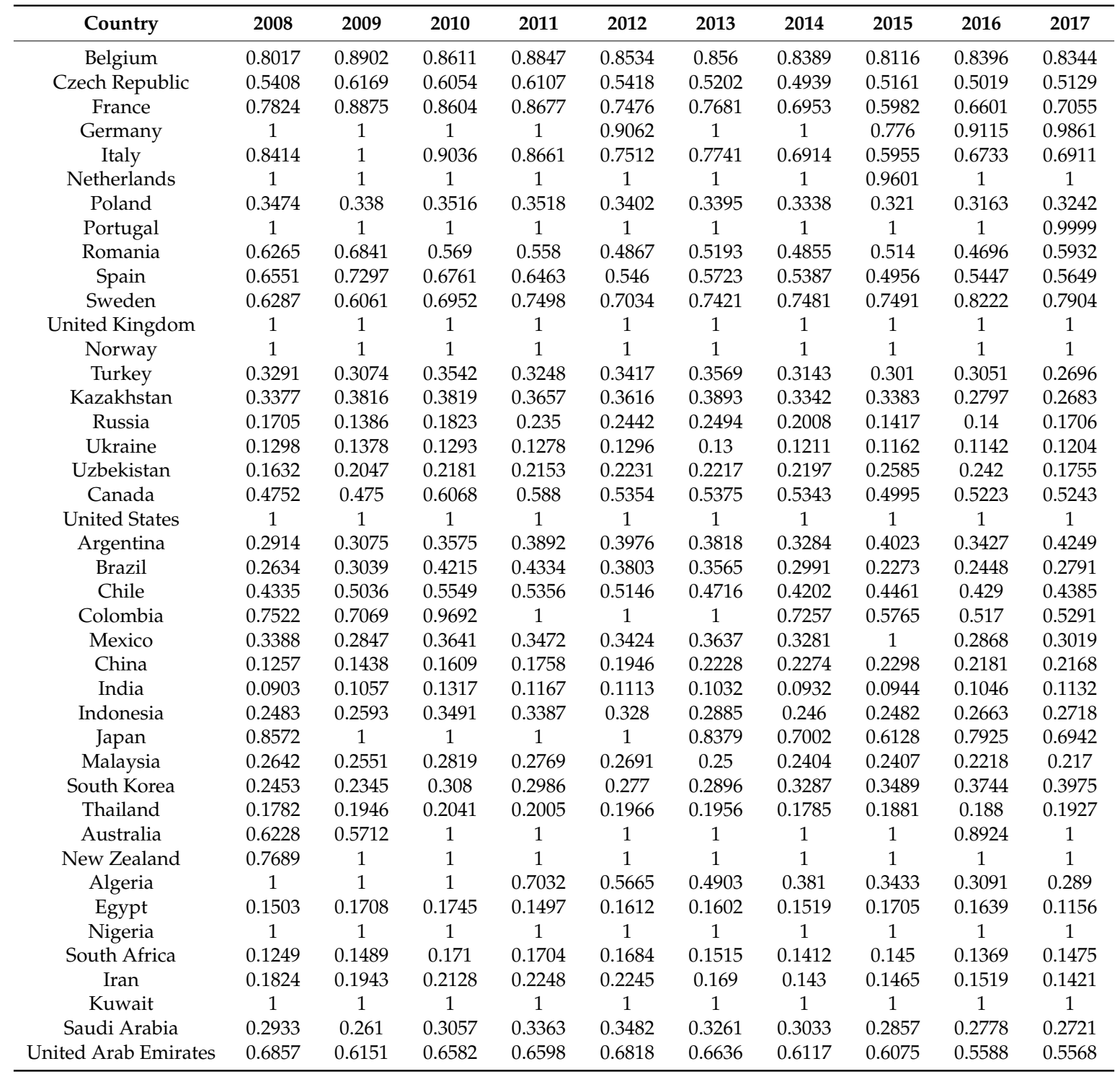

The above analysis results point out the efficient and inefficient terms in every year, where there are 12 efficient countries and 30 inefficient countries during the period from 2009 to 2011; from 2012 to 2013, there are 11 efficient countries and 31 inefficient countries; 2014 has 10 efficient countries, and 32 inefficient countries; 2008 and 2015 have nine efficient countries and 33 inefficient countries; the period of 2016-2017 has eight efficient countries and 34 inefficient countries. Thus, the quantity of inefficient countries is more than that of efficient countries. The empirical results indicate that United Kingdom, Norway, United States, Nigeria, and Kuwait always approach the efficiency without fluctuation.

\subsection{Ranking Countries}

Based on the scores shown in Table 2, this study gives in Table 3 the position of each of country in every year. 
Table 3. Raking countries during the period from 2008 to 2017.

\begin{tabular}{|c|c|c|c|c|c|c|c|c|c|c|}
\hline Country & 2008 & 2009 & 2010 & 2011 & 2012 & 2013 & 2014 & 2015 & 2016 & 2017 \\
\hline Belgium & 12 & 13 & 15 & 13 & 13 & 12 & 11 & 11 & 11 & 11 \\
\hline Czech Republic & 21 & 18 & 21 & 20 & 20 & 20 & 20 & 19 & 20 & 21 \\
\hline France & 13 & 14 & 16 & 14 & 15 & 15 & 15 & 16 & 15 & 13 \\
\hline Germany & 1 & 1 & 1 & 1 & 12 & 1 & 1 & 12 & 9 & 10 \\
\hline Italy & 11 & 1 & 14 & 15 & 14 & 14 & 16 & 17 & 14 & 15 \\
\hline Netherlands & 1 & 1 & 1 & 1 & 1 & 1 & 1 & 10 & 1 & 1 \\
\hline Poland & 24 & 25 & 29 & 27 & 30 & 29 & 25 & 28 & 25 & 25 \\
\hline Portugal & 1 & 1 & 1 & 1 & 1 & 1 & 1 & 1 & 1 & 9 \\
\hline Romania & 19 & 17 & 22 & 22 & 23 & 21 & 21 & 20 & 21 & 16 \\
\hline Spain & 17 & 15 & 18 & 19 & 19 & 18 & 18 & 22 & 17 & 17 \\
\hline Sweden & 18 & 20 & 17 & 16 & 16 & 16 & 12 & 13 & 12 & 12 \\
\hline United Kingdom & 1 & 1 & 1 & 1 & 1 & 1 & 1 & 1 & 1 & 1 \\
\hline Norway & 1 & 1 & 1 & 1 & 1 & 1 & 1 & 1 & 1 & 1 \\
\hline Turkey & 27 & 27 & 28 & 31 & 29 & 27 & 29 & 29 & 27 & 31 \\
\hline Kazakhstan & 26 & 24 & 25 & 26 & 26 & 24 & 24 & 27 & 29 & 32 \\
\hline Russia & 36 & 40 & 37 & 34 & 34 & 34 & 36 & 40 & 39 & 37 \\
\hline Ukraine & 39 & 41 & 42 & 41 & 41 & 41 & 41 & 41 & 41 & 40 \\
\hline Uzbekistan & 37 & 34 & 34 & 36 & 36 & 36 & 35 & 31 & 33 & 36 \\
\hline Canada & 22 & 23 & 20 & 21 & 21 & 19 & 19 & 21 & 18 & 20 \\
\hline United States & 1 & 1 & 1 & 1 & 1 & 1 & 1 & 1 & 1 & 1 \\
\hline Argentina & 29 & 26 & 27 & 25 & 24 & 25 & 27 & 24 & 24 & 23 \\
\hline Brazil & 31 & 28 & 24 & 24 & 25 & 28 & 31 & 35 & 32 & 28 \\
\hline Chile & 23 & 22 & 23 & 23 & 22 & 23 & 22 & 23 & 22 & 22 \\
\hline Colombia & 15 & 16 & 13 & 1 & 1 & 1 & 13 & 18 & 19 & 19 \\
\hline Mexico & 25 & 29 & 26 & 28 & 28 & 26 & 28 & 1 & 28 & 26 \\
\hline China & 40 & 39 & 40 & 38 & 38 & 35 & 34 & 34 & 35 & 34 \\
\hline India & 42 & 42 & 41 & 42 & 42 & 42 & 42 & 42 & 42 & 42 \\
\hline Indonesia & 32 & 31 & 30 & 29 & 31 & 32 & 32 & 32 & 31 & 30 \\
\hline Japan & 10 & 1 & 1 & 1 & 1 & 13 & 14 & 14 & 13 & 14 \\
\hline Malaysia & 30 & 32 & 33 & 33 & 33 & 33 & 33 & 33 & 34 & 33 \\
\hline South Korea & 33 & 33 & 31 & 32 & 32 & 31 & 26 & 25 & 23 & 24 \\
\hline Thailand & 35 & 35 & 36 & 37 & 37 & 37 & 37 & 36 & 36 & 35 \\
\hline Australia & 20 & 21 & 1 & 1 & 1 & 1 & 1 & 1 & 10 & 1 \\
\hline New Zealand & 14 & 1 & 1 & 1 & 1 & 1 & 1 & 1 & 1 & 1 \\
\hline Algeria & 1 & 1 & 1 & 17 & 18 & 22 & 23 & 26 & 26 & 27 \\
\hline Egypt & 38 & 37 & 38 & 40 & 40 & 39 & 38 & 37 & 37 & 41 \\
\hline Nigeria & 1 & 1 & 1 & 1 & 1 & 1 & 1 & 1 & 1 & 1 \\
\hline South Africa & 41 & 38 & 39 & 39 & 39 & 40 & 40 & 39 & 40 & 38 \\
\hline Iran & 34 & 36 & 35 & 35 & 35 & 38 & 39 & 38 & 38 & 39 \\
\hline Kuwait & 1 & 1 & 1 & 1 & 1 & 1 & 1 & 1 & 1 & 1 \\
\hline Saudi Arabia & 28 & 30 & 32 & 30 & 27 & 30 & 30 & 30 & 30 & 29 \\
\hline United Arab Emirates & 16 & 19 & 19 & 18 & 17 & 17 & 17 & 15 & 16 & 18 \\
\hline
\end{tabular}

As shown in Table 3, five countries including United Kingdom, Norway, United States, Nigeria, and Kuwait are always at the first position for the whole term. Germany with the first ranking is in $2008,2009,2010,2011,2013$, and 2014. Italy only obtains the first ranking in 2009. The Netherlands is mostly in the first position except for 2015. Portugal obtains first ranking from 2008 to 2016 and it is down to the ninth. Colombia gets the first ranking for three years as 2011, 2012, 2013. Japan attained first position during the period from 2009-2014. Australia is in the first ranking from 2010 to 2015, and in 2017. New Zealand reaches the first position except for 2008. Algeria approaches the first ranking in three years from 2008 to 2011. The remaining terms of Germany, Italy, Netherlands, Portugal, Colombia, Japan, Australia, New Zealand, Algeria, are ranked from 9 to 27. Belgium, Czech Republic, France, Poland, Romania, Spain, Sweden, Turkey, Kazakhstan, Russia, Ukraine, Uzbekistan, Canada, Argentina, Brazil, Chile, Mexico, China, India, Indonesia, Malaysia, South Korea, Thailand, Egypt, South Africa, Iran, Saudi Arabia, and United Arab Emirates stay at the low position without reaching the first position during whole term. Especially, India rank at the bottom position consecutively during the period of 2008-2017 except for 2010 where it raised one level with a ranking as forty-first. Ukraine has the last ranking in 2010. 
The above description specifies the ranking of an effect level in electrical energy sources. Increased population, simultaneously industrialization, and modernization all represent an important force that has an impact on accreting emissions. Therefore, the number of efficient countries with first contemporaneous ranking are reduced, from 2009 to 2017 down from 12 to eight countries. Furthermore, many countries such as the Czech Republic, Turkey, Kazakhstan, i.e., have yet to reach first position and thus face a downward trend. On the contrary, the United Kingdom, Norway, United States, Nigeria, and Kuwait maintain a sustainable economy and always stand at the highest ranking.

\subsection{Discussion}

The empirical results given in Section 4.2 point out the relationship between input and output factors of 42 countries during 2008-2017 when using electricity and reveal their positions in every year as well. The interplay pathway among selected inputs into selected desirable and undesirable outputs in the context of human growth activities in every country is explored based on Table 2. Most countries exhibit a fluctuation, according to each term; however, the United Kingdom, Norway, United States, Nigeria, and Kuwait always approach high scores as 1 and keep a stable position. They obtain an excellent interplay under all the circumstances.

On the other hand, other countries demonstrate a variation in each period. Portugal, The Netherlands, and New Zealand achieve good relations with scores of 1 over nine years, while Portugal kept in balance from 2008 to 2016 and displayed a downward trend in 2017 at 0.9999 . The Netherlands dropped in 2015, as its score is only at 0.9601 , and the primary score in 2008 is only 0.7689 , but its efforts to improve the interplay with upward mobility helped it reach to the high point in the next terms. Italy and Japan achieved a forward movement to obtain a maximum score in 2009; however, both they could not maintain a good relationship, which is down by the end. Algeria and Germany started with a brilliant mark with a maximum value in primal years; Algeria kept it in three years, consecutively, and dropped in the remaining years from 2011 to 2017; Germany has more flourish with a maximum score in six years and an upward trend in the final term from 0.776 to 0.9861 . Australia, Colombia, and Mexico fell in 2007, though they pushed up their scores in the next terms; particularly, Australia increased from 2009 to 2010 and held a stable score with a high position over six years consecutively; Colombia augmented in the first terms and decreased in the final terms; as its maximum score of 1 is for only three years from 2011 to 2013, Mexico has a sharp variation from 0.3281 to 1 within one year and then dropped deeply to 0.2868 in the next year. Consequently, these countries fluctuated over time; however, they still display a good interplay during some terms.

Besides, the 27 remaining countries have seen variations every year, thus failing reach to an excellent relationship. Their scores are usually lower than the standard value. Eight countries, i.e., Canada, Czech Republic, Romania, Sweden, Spain, United Arab Emirates, France, and Belgium, are at an average level with most of their values being under 0.5. Nineteen countries, i.e., India, South Africa, China, Ukraine, Egypt, Uzbekistan, Russia, Thailand, Iran, South Korea, Indonesia, Brazil, Malaysia, Argentina, Saudi Arabia, Turkey, Kazakhstan, Poland, and Chile, are seriously affected by emissions, as their valuations are all under 0.5 .

As a consequence, the economic development is accreting into producing emissions which are harmful for the environment. According to Chung's directional distance function [15], the performance in this case is refined by increasing the good output while simultaneously reducing the bad outputs. In the study, $\mathrm{CO}_{2}, \mathrm{CH}_{4}$, and $\mathrm{N}_{2} \mathrm{O}$ must decline, but at the same time the GDP still must increase. In addition, the electricity consumption can be reduced when the electricity usage should the saved and replace high-capacity equipment with low-capacity equipment in order to diminish energy consumption. That way, emissions can dwindle to avoid a contaminated environment and climate change, the effect of electricity consumption on climate change was tested by Philli-Sihvola [44]; further, with the inefficient terms, the performance among inputs and desirable and undesirable outputs can be improved. 


\section{Conclusions}

Electricity provides humans with light and operation of machines. Then, if a population is at a high level, the consumption of electricity will increase. As a result, economic growth will be enhanced by displayed in the GDP index; however, electricity production and use brings disadvantages of emitting undesirable factors $\left(\mathrm{CO}_{2}, \mathrm{CH}_{4}, \mathrm{~N}_{2} \mathrm{O}\right)$. Therefore, the study proposes an undesirable outputs model to measure the performance of the elements that relate to the EC process.

For the characteristics of dealing with fixed bad and good outputs, an undesirable outputs model is used help the study formulate scores. The empirical values demonstrate interplay among variables, ranking, and variable pathways of every country in every year. Forty-two countries are defined as efficiency or inefficient after applying an undesirable outputs model to analyzing their performance. The analysis results denote that the United Kingdom, Norway, United States, Nigeria, and Kuwait show stable efficiency and retain a good relationship for the whole term; other countries have changed consecutively every time.

For the 42 countries we not only know about the interplay among inputs, desirable and undesirable outputs but can also understand the quantitative analysis that affect level of emissions. Based on the principle of undesirable outputs model, desirable outputs i.e., GDP should be increased; undesirable outputs including $\mathrm{CO}_{2}, \mathrm{CH}_{4}$, and $\mathrm{N}_{2} \mathrm{O}$, and inputs, i.e., electricity consumption at the inefficient terms will be reduced, by the way the efficiency will be improved. In addition, they find $t a$ direction to restore balance to their ecosystems.

In general, the study summarizes the basic data of EC and specifies a relationship between EC and related factors; however, limitations remain. First, the inputs and outputs of all countries are not listed, so that the future research should expand to add more countries. Second, the interplay will become deeper when calculations include enough factors. Further study should investigate this in order to obtain more inputs, i.e., capital, assets, and output variables, i.e., revenue. Third, the study only needs the efficiency in the past term through the undesirable outputs model, so further studies could utilize more models to predict the future terms. Fourth, the future direction will use the Spearman correlation coefficient to have a statistical measure of a relationships between paired data.

Author Contributions: C.-N.W. guided the analysis method, and the research direction, found the solutions, and edited the content; Q.C.L. designed research framework, analyzed the empirical result and wrote; T.K.L.N. collected and analyzed the data. All authors contributed in issuing the final result.

Funding: This research was partly supported by MOST107-2622-E-992-012-CC3 from the Ministry of Sciences and Technology in Taiwan.

Acknowledgments: The authors appreciate the support from National Kaohsiung University of Science and Technology, Ministry of Sciences and Technology in Taiwan.

Conflicts of Interest: The authors declare no conflict of interest 


\section{Appendix A}

Table A1. Statistics of the 42 countries over the period of 2008-2011.

\begin{tabular}{ccccccc}
\hline Years & Population & EC (TWh) & $\mathbf{C O}_{\mathbf{2}}$ (Mtons) & $\mathbf{C H}_{\mathbf{4}}$ (Mtons) & $\mathbf{N}_{\mathbf{2}} \mathbf{O}$ (Mtons) & GDP (Million in USD) \\
\hline \multirow{4}{*}{2008} & $1,324,655,000$ & 3907.229 & 2598.6199 & 0.1445 & 0.0271 & $14,718,582$ \\
& $2,652,340$ & 18.517 & 12.3153 & 0.0007 & 0.0001 & $29,549.44$ \\
& $118,126,627.26$ & 373.5982 & 248.4727 & 0.0138 & 0.0026 & $1,336,946.326$ \\
& $263,672,064.05$ & 728.7291 & 484.6632 & 0.027 & 0.0051 & $2,411,815.529$ \\
\hline \multirow{4}{*}{2009} & $1,331,260,000$ & 3724.658 & 2477.1955 & 0.1378 & 0.0258 & $14,418,739$ \\
& $2,818,939$ & 18.051 & 12.0054 & 0.0007 & 0.0001 & $33,689.22$ \\
& $119,287,116.55$ & 371.3682 & 246.9896 & 0.0137 & 0.0026 & $1,268,097.807$ \\
& $266,092,473.27$ & 728.332 & 484.3991 & 0.0269 & 0.0051 & $2,386,203.268$ \\
\hline \multirow{2}{*}{2010} & $1,337,705,000$ & 3894.367 & 2598.6199 & 0.1445 & 0.0271 & $14,964,372$ \\
& $2,998,083$ & 20.876 & 12.3153 & 0.0007 & 0.0001 & $39,332.77$ \\
& $120,434,614.83$ & 397.1979 & 248.4727 & 0.0138 & 0.0026 & $1,393,321.39$ \\
& $268,462,393.21$ & 786.178 & 484.6632 & 0.027 & 0.0051 & $2,506,496.099$ \\
\hline \multirow{2}{*}{2011} & $1,344,130,000$ & 4051.605 & 2694.6415 & 0.1499 & 0.0281 & $15,517,926$ \\
& $3,191,051$ & 23.679 & 15.7484 & 0.0009 & 0.0002 & $45,915.19$ \\
& $121,536,746.24$ & 409.9938 & 272.6786 & 0.0152 & 0.0029 & $1,549,594.858$ \\
& $270,791,913.9$ & 827.6549 & 550.4567 & 0.0306 & 0.0057 & $2,671,950.305$ \\
\hline
\end{tabular}

Table A2. Statistics of the 42 countries over the period of 2012-2017.

\begin{tabular}{ccccccc}
\hline Years & Population & EC (TWh) & $\mathbf{C O}_{\mathbf{2}}$ (Mtons) & $\mathbf{C H}_{\mathbf{4}}$ (Mtons) & $\mathbf{N}_{\mathbf{2}} \mathbf{O}$ (Mtons) & GDP (Million in USD) \\
\hline \multirow{4}{*}{2012} & $1,350,695,000$ & 4326.079 & 2877.188 & 0.16 & 0.03 & $16,155,255$ \\
& $3,395,556$ & 25.399 & 16.8924 & 0.0009 & 0.0002 & $51,821.57$ \\
& $122,670,658.43$ & 419.9453 & 279.1316 & 0.0155 & 0.0029 & $1,583,732.445$ \\
& $273,099,786.91$ & 851.7249 & 566.4128 & 0.0315 & 0.0059 & $2,799,627.018$ \\
\hline \multirow{2}{*}{2013} & $1,357,380,000$ & 4717.568 & 3137.5601 & 0.1745 & 0.0327 & $16,691,517$ \\
& $3,598,385$ & 23.689 & 15.7551 & 0.0009 & 0.0002 & $57,690.45$ \\
& $123,810,535.81$ & 432.4245 & 287.745 & 0.016 & 0.003 & $1,622,822.758$ \\
& $275,389,972.61$ & 899.751 & 598.4121 & 0.0333 & 0.0062 & $2,899,088.887$ \\
\hline \multirow{2}{*}{2014} & $1,364,270,000$ & 4938.623 & 3284.5794 & 0.183 & 0.0343 & $17,427,609$ \\
& $3,782,450$ & 24.625 & 16.3776 & 0.001 & 0.0002 & $63,067.08$ \\
& $124,952,217.6$ & 441.3991 & 292.8808 & 0.0163 & 0.0031 & $1,662,353.067$ \\
& $277,690,414.5$ & 927.2612 & 616.5223 & 0.0343 & 0.0064 & $3,046,071.083$ \\
\hline \multirow{4}{*}{2015} & $1,371,220,000$ & 5103.889 & 3301.0023 & 0.1836 & 0.0344 & $18,120,714$ \\
& $3,935,794$ & 25.268 & 17.848 & 0.001 & 0.0002 & $66,903.8$ \\
& $126,084,336.38$ & 448.5672 & 292.5948 & 0.0163 & 0.0031 & $1,572,917.053$ \\
& $279,993,795.16$ & 946.811 & 619.273 & 0.0344 & 0.0065 & $3,157,505.409$ \\
\hline \multirow{2}{*}{2016} & $1,378,665,000$ & 5366.78 & 3471.2873 & 0.1931 & 0.0362 & $1,862,4475$ \\
& $4,052,584$ & 24.5605 & 16.2416 & 0.0009 & 0.0002 & $67,067.57$ \\
& $127,216,593.57$ & 459.7215 & 307.2145 & 0.0171 & 0.0031 & $1,596,048.935$ \\
& $282,345,525.38$ & 977.6329 & 635.8452 & 0.0354 & 0.0066 & $3,243,650.311$ \\
\hline \multirow{2}{*}{2017} & $1,386,395,000$ & 5683.42 & 3779.929 & 0.2102 & 0.0394 & $19,390,604$ \\
& $4,136,528$ & 24.4774 & 16.2794 & 0.0009 & 0.0002 & $48,717.69$ \\
& $128,333,654.5$ & 471.4782 & 313.5707 & 0.0174 & 0.0033 & $1,692,506.563$ \\
& $284,721,026.7$ & 1010.7354 & 672.2199 & 0.0374 & 0.007 & $3,412,183.899$ \\
\hline
\end{tabular}

Table A3. Case Processing Summary.

\begin{tabular}{ccccccc}
\hline \multirow{2}{*}{ Factors } & \multicolumn{9}{c}{ Cases } \\
\cline { 2 - 7 } & \multicolumn{2}{c}{ Valid } & \multicolumn{2}{c}{ Missing } & \multicolumn{2}{c}{ Total } \\
\cline { 2 - 7 } & $\mathbf{N}$ & Percent & N & Percent & N & Percent \\
\hline (I) Population & 417 & $100.00 \%$ & 0 & $0.00 \%$ & 42 & $100.00 \%$ \\
(I) Electricity consumption (TWh) & 417 & $100.00 \%$ & 0 & $0.00 \%$ & 42 & $100.00 \%$ \\
(O) GDP (million USD) & 417 & $100.00 \%$ & 0 & $0.00 \%$ & 42 & $100.00 \%$ \\
(Obad) $\mathrm{CO}_{2}$ (Mtons) & 417 & $100.00 \%$ & 0 & $0.00 \%$ & 42 & $100.00 \%$ \\
(Obad) $\mathrm{CH}_{4}$ (Mtons) & 417 & $100.00 \%$ & 0 & $0.00 \%$ & 42 & $100.00 \%$ \\
(Obad) $\mathrm{N}_{2} \mathrm{O}$ (Mtons) & 417 & $100.00 \%$ & 0 & $0.00 \%$ & 42 & $100.00 \%$ \\
\hline
\end{tabular}


Table A4. Person's correlation over the period of 2008-2012.

\begin{tabular}{|c|c|c|c|c|c|c|c|}
\hline Indicators & Year & Population & EC (TWh) & $\mathrm{CO}_{2}$ (Mtons) & $\mathrm{CH}_{4}$ (Mtons) & $\mathrm{N}_{2} \mathrm{O}$ (Mtons) & GDP (Million USD) \\
\hline Population & \multirow{6}{*}{2008} & 1 & 0.580126 & 0.580126 & 0.580341 & 0.579862 & 0.303741 \\
\hline EC (TWh) & & 0.580126 & 1 & 1 & 0.999999 & 0.999986 & 0.901139 \\
\hline $\mathrm{CO}_{2}$ (Mtons) & & 0.580126 & 1 & 1 & 0.999999 & 0.999986 & 0.901139 \\
\hline $\mathrm{CH}_{4}$ (Mtons) & & 0.580341 & 0.999999 & 0.999999 & 1 & 0.999985 & 0.901071 \\
\hline $\mathrm{N}_{2} \mathrm{O}$ (Mtons) & & 0.579862 & 0.999986 & 0.999986 & 0.999985 & 1 & 0.901355 \\
\hline GDP (million USD) & & 0.303741 & 0.901139 & 0.901139 & 0.901071 & 0.901355 & 1 \\
\hline Population & \multirow{6}{*}{2009} & 1 & 0.616812 & 0.616812 & 0.616607 & 0.616654 & 0.33962 \\
\hline EC (TWh) & & 0.616812 & 1 & 1 & 0.999999 & 0.999985 & 0.894023 \\
\hline $\mathrm{CO}_{2}$ (Mtons) & & 0.616812 & 1 & 1 & 0.999999 & 0.999985 & 0.894023 \\
\hline $\mathrm{CH}_{4}$ (Mtons) & & 0.616607 & 0.999999 & 0.999999 & 1 & 0.999984 & 0.894111 \\
\hline $\mathrm{N}_{2} \mathrm{O}$ (Mtons) & & 0.616654 & 0.999985 & 0.999985 & 0.999984 & 1 & 0.893678 \\
\hline GDP (million USD) & & 0.33962 & 0.894023 & 0.894023 & 0.894111 & 0.893678 & 1 \\
\hline Population & \multirow{6}{*}{2010} & 1 & 0.633979 & 0.576015 & 0.576229 & 0.575756 & 0.380058 \\
\hline EC (TWh) & & 0.633979 & 1 & 0.994505 & 0.994535 & 0.994407 & 0.900126 \\
\hline $\mathrm{CO}_{2}$ (Mtons) & & 0.576015 & 0.994505 & 1 & 0.999999 & 0.999986 & 0.934326 \\
\hline $\mathrm{CH}_{4}$ (Mtons) & & 0.576229 & 0.994535 & 0.999999 & 1 & 0.999985 & 0.93427 \\
\hline $\mathrm{N}_{2} \mathrm{O}$ (Mtons) & & 0.575756 & 0.994407 & 0.999986 & 0.999985 & 1 & 0.934449 \\
\hline GDP (million USD) & & 0.380058 & 0.900126 & 0.934326 & 0.93427 & 0.934449 & 1 \\
\hline Population & \multirow{6}{*}{2011} & 1 & 0.664182 & 0.664182 & 0.664216 & 0.664145 & 0.419236 \\
\hline EC (TWh) & & 0.664182 & 1 & 1 & 1 & 0.999989 & 0.898789 \\
\hline $\mathrm{CO}_{2}$ (Mtons) & & 0.664182 & 1 & 1 & 1 & 0.999989 & 0.898789 \\
\hline $\mathrm{CH}_{4}$ (Mtons) & & 0.664216 & 1 & 1 & 1 & 0.999989 & 0.898727 \\
\hline $\mathrm{N}_{2} \mathrm{O}$ (Mtons) & & 0.664145 & 0.999989 & 0.999989 & 0.999989 & 1 & 0.899497 \\
\hline GDP (million USD) & & 0.419236 & 0.898789 & 0.898789 & 0.898727 & 0.899497 & 1 \\
\hline Population & \multirow{6}{*}{2012} & 1 & 0.680572 & 0.680718 & 0.680613 & 0.680276 & 0.440727 \\
\hline EC (TWh) & & 0.680572 & 1 & 0.999997 & 0.999997 & 0.999983 & 0.902231 \\
\hline $\mathrm{CO}_{2}$ (Mtons) & & 0.680718 & 0.999997 & 1 & 1 & 0.999989 & 0.902234 \\
\hline $\mathrm{CH}_{4}$ (Mtons) & & 0.680613 & 0.999997 & 1 & 1 & 0.999988 & 0.902301 \\
\hline $\mathrm{N}_{2} \mathrm{O}$ (Mtons) & & 0.680276 & 0.999983 & 0.999989 & 0.999988 & 1 & 0.90262 \\
\hline GDP (million USD) & & 0.440727 & 0.902231 & 0.902234 & 0.902301 & 0.90262 & 1 \\
\hline
\end{tabular}

Table A5. Person's correlation over the period of 2013-2017.

\begin{tabular}{|c|c|c|c|c|c|c|c|}
\hline Indicators & Year & Population & EC (TWh) & $\mathrm{CO}_{2}$ (Mtons) & $\mathrm{CH}_{4}$ (Mtons) & $\mathrm{N}_{2} \mathrm{O}$ (Mtons) & GDP (Million USD) \\
\hline Population & \multirow{5}{*}{2013} & 1 & 0.695153 & 0.696013 & 0.695992 & 0.695301 & 0.464744 \\
\hline EC (TWh) & & 0.695153 & 1 & 0.999998 & 0.999998 & 0.999988 & 0.907294 \\
\hline $\mathrm{CO}_{2}$ (Mtons) & & 0.696013 & 0.999998 & 1 & 1 & 0.999988 & 0.907197 \\
\hline $\mathrm{N}_{2} \mathrm{O}$ (Mtons) & & 0.695301 & 0.999988 & 0.999988 & 0.999987 & 1 & 0.90767 \\
\hline GDP (million USD) & & 0.464744 & 0.907294 & 0.907197 & 0.907255 & 0.90767 & 1 \\
\hline $\mathrm{CO}_{2}$ (Mtons) & \multirow{4}{*}{2014} & 0.705663 & 0.999991 & 1 & 0.999961 & 0.999989 & 0.907172 \\
\hline $\mathrm{CH}_{4}$ (Mtons) & & 0.705031 & 0.999952 & 0.999961 & 1 & 0.999947 & 0.907122 \\
\hline $\mathrm{N}_{2} \mathrm{O}$ (Mtons) & & 0.705695 & 0.99998 & 0.999989 & 0.999947 & 1 & 0.906706 \\
\hline GDP (million USD) & & 0.480833 & 0.907172 & 0.907172 & 0.907122 & 0.906706 & 1 \\
\hline Population & \multirow{2}{*}{2015} & 1 & 0.714941 & 0.708444 & 0.708326 & 0.70894 & 0.491955 \\
\hline EC (TWh) & & 0.714941 & 1 & 0.999494 & 0.999493 & 0.999839 & 0.908562 \\
\hline Population & \multirow{6}{*}{2016} & 1 & 0.724975 & 0.718889 & 0.71891 & 0.720908 & 0.490153 \\
\hline EC (TWh) & & 0.724975 & 1 & 0.998089 & 0.9981 & 0.999912 & 0.8947 \\
\hline $\mathrm{CO}_{2}$ (Mtons) & & 0.718889 & 0.998089 & 1 & 1 & 0.998155 & 0.897223 \\
\hline $\mathrm{CH}_{4}$ (Mtons) & & 0.71891 & 0.9981 & 1 & 1 & 0.998165 & 0.897175 \\
\hline $\mathrm{N}_{2} \mathrm{O}$ (Mtons) & & 0.720908 & 0.999912 & 0.998155 & 0.998165 & 1 & 0.898646 \\
\hline GDP (million USD) & & 0.490153 & 0.8947 & 0.897223 & 0.897175 & 0.898646 & 1 \\
\hline Population & \multirow{5}{*}{2017} & 1 & 0.73631 & 0.73631 & 0.736469 & 0.73605 & 0.508286 \\
\hline EC (TWh) & & 0.73631 & 1 & 1 & 1 & 0.999992 & 0.891115 \\
\hline $\mathrm{CO}_{2}$ (Mtons) & & 0.73631 & 1 & 1 & 1 & 0.999992 & 0.891115 \\
\hline $\mathrm{CH}_{4}$ (Mtons) & & 0.736469 & 1 & 1 & 1 & 0.999992 & 0.89107 \\
\hline $\mathrm{N}_{2} \mathrm{O}$ (Mtons) & & 0.73605 & 0.999992 & 0.999992 & 0.999992 & 1 & 0.891228 \\
\hline
\end{tabular}




\section{Appendix B}

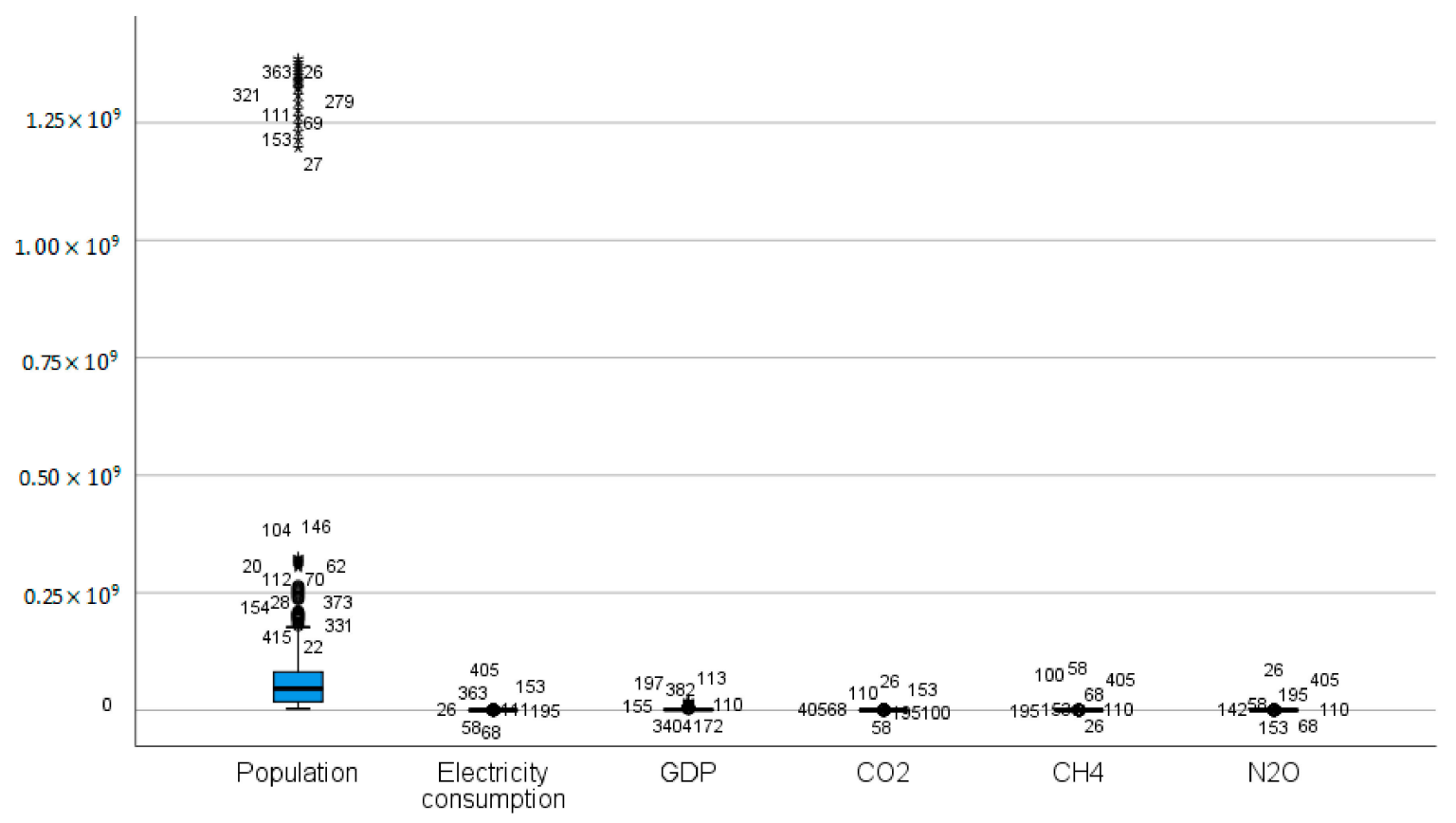

Figure A1. Boxplot of inputs and outputs.

\section{References}

1. Richard, F.H.; Jonathan, G.K. Electricity Consumption and Economic Growth: A New Relationship with Significant Consequences. Electr. J. 2015, 28, 72-84. [CrossRef]

2. Tewathia, N. Determinant of the Household Electricity Consumption: A Case Study of Delhi. Int. J. Energy Econ. Policy 2014, 4, 337-348.

3. Hameed, L.; Khan, A.A. Population Growth and Increase in Domestic Electricity Consumption in Pakistan: A Case Study of Bahawalpur City. J. Soc. Sci. 2016, 2, 27-33.

4. Lu, W.-C. Electricity Consumption and Economic Growth: Evidence from 17 Taiwanese industries. Sustainability 2016, 9, 50. [CrossRef]

5. Enu, P.; Havi, E.D.K. Influence of Electricity Consumption on Economic Growth in Ghana. Int. J. Econ. Commer. Manag. 2014, II, 1-20.

6. Altinay, G.; Karagol, E. Electricity Consumption and Economic Growth: Evidence from Turkey. Energy Econ. 2005, 27, 849-856. [CrossRef]

7. Ologun, O.O.; Wara, S.T. Carbon Footprint Evaaluation and Reduction as a Climate Change Mitigation Tool-Case Study of Federal University of Agriculture Abeokuta, Ogun, State, Nigeria. Int. J. Renew. Energy Res. 2014, 4, 176-181.

8. To, W.M.; Peter, K.C.L. GHG emissions from electricity consumption: A case study of Hong Kong from 2002 to 2015 and trends to 2030. J. Clean. Prod. 2017, 165, 589-598. [CrossRef]

9. Hooi, H.L.; Russell, S. $\mathrm{CO}_{2}$ emissions, electricity consumption and output in ASEAN. Appl. Energy 2010, 87, 1858-1864. [CrossRef]

10. Mohammed Redha Qader. Electricity Consumption and GHG Emissions in GCC Countries. Energies 2009, 2, 1201-1213. [CrossRef]

11. Albiman, M.M.; Suleiman, N.N.; Baka, M.O. The Relationship between Energy Consumption, $\mathrm{CO}_{2}$ Emissions and Economic Growth in Tanzania. Int. J. Energy Sect. Manag. 2015, 9, 361-375. [CrossRef]

12. Battery and Energy Technologies. Available online: https://www.mpoweruk.com (accessed on 10 August 2018).

13. Seyed Esmaeili, F.; Rostamy-Malkhalifed, M. Data Envelopment Analysis with Fixed Inputs, Undesirable Outputs and Negative Data. J. Data Envel. Anal. Decis. Sci. 2017, 2017, dea-00140. [CrossRef] 
14. Lawrence, M.S.; Joe, Z. Modeling Undesirable Factors in Efficiency Evaluation. Eur. J. Oper. Res. 2002, 142, 16-20. [CrossRef]

15. Chung, Y.H.; Färe, R.; Grosskopf, S. Productivity and Undesirable Outputs: A Directional Distance Function Approach. J. Environ. Manag. 1997, 51, 229-240. [CrossRef]

16. Chen, W.-J.; He, G. Electricity Consumption and its Impact Factors: Based on the Nonparametric Model. Syst. Eng. Theory Pract. 2009, 29, 92-97. [CrossRef]

17. Gajowniczek, K.; Zabkowski, T. Short term electricity forecasting based on user behavior using individual smart meter data. Intell. Fuzzy Syst. 2015, 30, 223-234. [CrossRef]

18. Gajowniczek, K.; Ząbkowski, T. Two-stage electricity demand modelling using machine learning algorithms. Energies 2017, 10, 1547. [CrossRef]

19. Singh, S.; Yassine, A. Big data mining of energy time series for behavioral analytics and energy consumption forecasting. Energies 2018, 11, 452. [CrossRef]

20. Paul, E.H.; Tom, S.C.; Robert, G.H. Life cycle greenhouse gas emissions from electricity generation: A comparative analysis of Australian energy source. Energies 2012, 5, 872-897. [CrossRef]

21. Hanqin, T.; Guangsheng, C.; Chaoqun, L. Global Methane and Nitrous Oxide Emissions from Terrestrial Ecosystems due to Multiple Environmental Changes. Ecosyst. Health Sustain. 2015, 1, 1-20. [CrossRef]

22. Jiang, L.; Ou, X.; Ma, L.; Li, Z.; Ni, W. Life-cycle GHG Emission Factors of Final Energy in China. Energy Procedia 2013, 37, 2848-2855. [CrossRef]

23. Timo, A.S.; Olli, V.; Laura, S.; Matti, K. Greenhouse Gas Emissions of Hydropower in the Mekong River Basin. Environ. Res. Lett. 2018, 13, 034030. [CrossRef]

24. Yasutoshi, S.; Satoshi, D.; Kanako, T. The $\mathrm{CO}_{2}$ Emission Factor of Water in Japan. Water 2012, 4, 759-769. [CrossRef]

25. Xiaochun, Z.; Nathan, P.M.; Ken, C. Key Factors for Assessing Climate Benefits of Natural Gas Versus Coal Electricity Generation. Environ. Res. Lett. 2014, 9, 114022. [CrossRef]

26. Chang-Sang, C.; Jae-Hwan, S.; Ki-Kyo, L.; Tae-Mi, Y. Development of Methane and Nitrous Oxide Emission Factors for the Biomass Fired Circulating Fluidized Bed Combustion Power Plant. Sci. World J. 2012. [CrossRef]

27. Yuxuan, W.; Tianye, S. Life Cycle Assessment of $\mathrm{CO}_{2}$ Emissions from Wind Power Plants: Methodology and Case Studies. Renew. Energy 2012, 43, 30-36. [CrossRef]

28. Ma, C.M.; Ge, Q.S. Method for Calculating $\mathrm{CO}_{2}$ Emissions from the Power Sector at the Provincial Level in China. Adv. Clim. Chang. Res. 2014, 5, 92-99. [CrossRef]

29. Greg, S.; Ines, A.; Constantine, S. Assessing the Evolution of Power Sector Carbon Intensity in the United States. Environ. Res. Lett. 2018, 13. [CrossRef]

30. Tone, K. Dealing with Undesirable Outputs in DEA: A Slacks-Based Measure (SBM) Approach; National Graduate Institute for Policy Studies: Tokyo, Japan, 2003.

31. Amiteimoori, A.; Toloie-Eshlaghi, A.; Homayoonfar, M. Efficiency Measurement in Two-Stage Network Structures Considering Undesirable Outputs. Int. J. Ind. Math. 2014, 6, 65-72.

32. Scheel, H. Undesirable Outputs in Efficiency Valuations. Eur. J. Oper. Res. 2001, 132, 400-410. [CrossRef]

33. Gongbing, B.; Liang, L.; Jie, W. Radial and non-radial DEA Models Undesirable Outputs: An Application to OECD Countries. Int. J. Sustain. Soc. 2010, 2. [CrossRef]

34. Tone, K.; Tsutsui, M. Applying an Efficiency Measure of Desirable and Undesirable Outputs in DEA to U.S. Electric Utilities. J. Cent. Cathedra 2001, 4, 236-249. [CrossRef]

35. Wen-Hsien, T.; Hsin-Li, L.; Chid-Hao, Y.; Chung-Chen, H. Input-Output Analysis for Sustainability by Using DEA Method: A Comparison Study between European and Asian Countries. Sustainability 2016, 8, 1230. [CrossRef]

36. You, S.; Yan, H. A New Approach in Modelling Undesirable Output in DEA Model. J. Oper. Res. Soc. 2001, 62, 2146-2156. [CrossRef]

37. Flavia, D.C.C.; Daisy, A.D.N.R.; Roberta, T.R. Energy Efficiency Analysis of BRICS Countries: A Study Using Data Envelopment Analysis. Gest. Prod. 2016, 23, 192-203. [CrossRef]

38. Electricity Consumption. Available online: https://yearbook.enerdata.net (accessed on 8 July 2018).

39. Population, GDP. Available online: https:/ / data.worldbank.org/indicator (accessed on 8 July 2018).

40. $\mathrm{CO}_{2}, \mathrm{CH}_{4}, \mathrm{~N}_{2} \mathrm{O}$. Available online: https:/ / www.epa.gov/sites/production/files/2015-08/sgec_tool_v3_2.xls (accessed on 8 July 2018). 
41. Tone, K. A slack-based measure of super-efficiency in data envelopment analysis. Eur. J. Oper. Res. 2002, 143, 34-41. [CrossRef]

42. Tone, K. A slacks-based measure of efficiency in data envelopment analysis. Eur. J. Oper. Res. 2001, 130, 498-509. [CrossRef]

43. Charnes, A.; Cooper, W.W. Programming with linear fractional functionals. Nav. Res. Logist. Q. 1962, 9, 181-186. [CrossRef]

44. Pilli-Sihvola, K.; Aatola, P.; Ollikainen, M.; Tuomenvirta, H. Climate change and electricity consumption-Witnessing increasing or decreasing use and costs? Energy Policy 2010, 38, 2409-2419. [CrossRef]

(C) 2018 by the authors. Licensee MDPI, Basel, Switzerland. This article is an open access article distributed under the terms and conditions of the Creative Commons Attribution (CC BY) license (http:// creativecommons.org/licenses/by/4.0/). 